\title{
Edoardo Ascari, a man to whom Haematologica owes much
}

\section{Carlo Balduini}

President of the Ferrata-Storti Foundation, Pavia, Italy

E-mail: CARLO BALDUINI - carlo.balduini@unipv.it.doi:10.3324/haematol.2021.279273

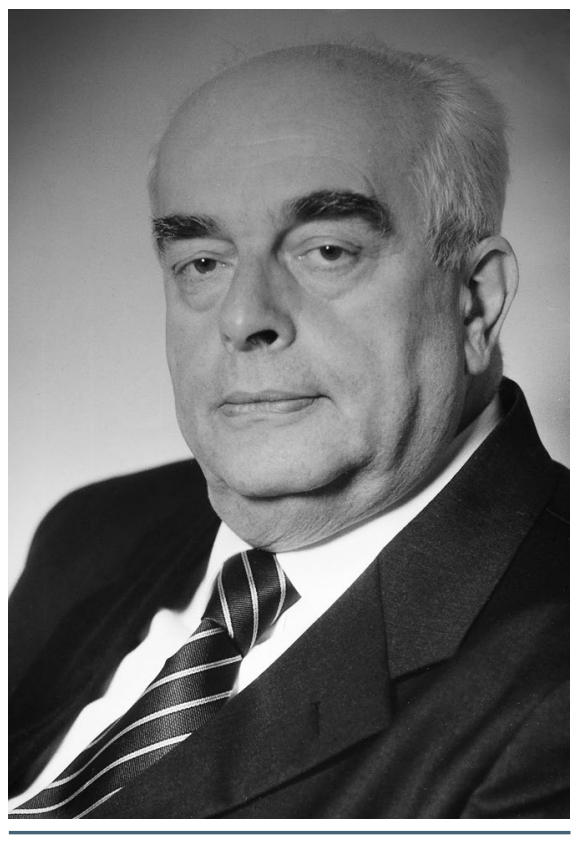

Edoardo Ascari 1932-2021.

E doardo Ascari, former Editor-in-Chief of Haematologica and President of the Ferrata-Storti Foundation, passed away peacefully in the morning of May 14 this year after a long and fruitful life.

Ascari was born in Modena, Italy, in 1932 and in this city he met the two most important people in his life. The first was the woman destined to become his wife and to give him two wonderful children. The second was Edoardo Storti, who at the time headed the Department of Internal Medicine of Modena University. Once he graduated in Medicine, Ascari became a pupil of Storti and began to take his first steps in the field of Hematology, focusing mainly on defects of blood coagulation. These were the times when infusions of fresh plasma and cryoprecipitate were being used to improve hemostasis of hemophiliacs and it is thanks to their prophylactic use that Storti and his collaborators, first and foremost Ascari, were, for the first time, able to practice synovectomy successfully to prevent relapsing hemarthrosis. When, in 1969, Storti became Director of the Medical Clinic of the University of Pavia, Ascari followed him and there organized a hemostasis laboratory that was very advanced for those times. In the 1980s, having become full Professor of Internal Medicine, Ascari took over the direction of Clinical Medicine in Pavia and led numerous collaborators destined to make important contributions in various fields of Hematology. Under his direction, the Pavia Medical Clinic continued to be a reference center for hemorrhagic and thrombotic diseases, as well as for many other neoplastic and non-neoplastic blood disorders.
Ascari played an important role in Hematology not only as a researcher at the beginning of his career and then as the mentor of an important school of Hematology, but also as Editor-in-Chief from 1990 to 2002 of Haematologica, the journal founded by Adolfo Ferrata in 1920, and as President of the Ferrata-Storti Foundation, the institution founded by Storti mainly to manage and support the journal, from 2002 to 2019. Directly or indirectly, he therefore took care of Haematologica for nearly 30 years.

When Ascari took over as Editor-in-Chief of Haematologica, the journal was in a critical condition. The number of submitted manuscripts was small, the selection of the articles to be published could not therefore be too strict and the result of this was that the citations received by the journal were few. This was a vicious circle from which it was difficult to escape. Ascari, among the very first to do so in the field of Hematology, took the courageous decision to make the journal open access, knowing that this choice could have led to a further decline in subscriptions. It was, however, a winning move: the number of citations increased which meant that the number of authors who wanted to publish in the journal also increased. The selection of the papers to be published could become ever more discerning, and a virtuous circle was triggered, which progressively enhanced the prestige of the journal and led it to now being one of the best reputed in the field of Hematology.

The Ferrata-Storti Foundation and all the people who work today to make the publication of Haematologica possible remember Edoardo Ascari with great affection and gratitude. 